\title{
Physical Activity, Self-Efficacy, and Perceived Exertion Among Adolescents
}

\author{
Lorraine B. Robbins, ${ }^{1 *}$ Nola J. Pender, ${ }^{1 \dagger}$ David L. Ronis, ${ }^{1,2} \ddagger$ \\ Anamaria S. Kazanis, ${ }^{1,3 \S}$ Monika B. Pis ${ }^{1 \uparrow}$

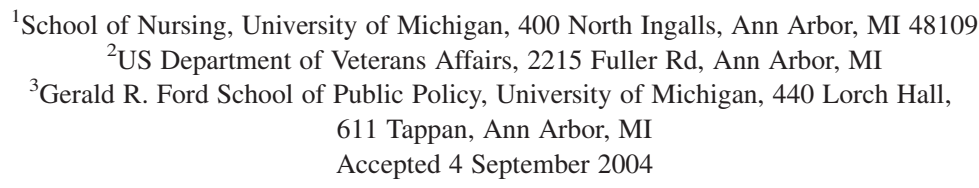

\begin{abstract}
The relationship of self-efficacy, a sense of confidence in personal physical activity (PA) skills, to perceived exertion during activity was explored among 168 African American and European American boys and girls between 9 and 17 years of age. Participants walked/ran on a treadmill at a speed equivalent to $60 \%$ of their peak $\mathrm{VO}_{2}$ for 20 minutes and provided ratings of exertion every 4 minutes. Pre-activity self-efficacy predicted perceived exertion for boys only. Girls were lower than boys in pre-activity self-efficacy and subsequently reported greater perceived exertion. For both genders, lower perceived exertion during PA resulted in higher post-activity selfefficacy. Uncomfortable perceptions of exertion during initial efforts to increase PA are likely to discourage future activity. Interventions that can lower perceptions of exertion may enhance self-efficacy and promote a sense of competence in PA skills. (๑) 2004 Wiley Periodicals, Inc. Res Nurs Health 27:435446, 2004
\end{abstract}

Keywords: physical activity; exercise; self-efficacy; perceived exertion; adolescents

Accumulating scientific evidence indicates that significant health benefits are derived from participation in regular physical activity (PA; United States Department of Health and Human Services [USDHHS], 1996). PA is defined as any body movement produced by skeletal contraction, which results in energy expenditure (Huddleston, 2002). Not more than $50 \%$ of children participate in any routine PA (Bar-Or et al., 1998; McGinnis, 1992), and participation in all types of PA decreases strikingly during adolescence (Stone, McKenzie, Welk, \& Booth, 1998). Data on PA are unclear regarding at what age the decline begins and whether the rate of decline is linear (Stone et al.). During adolescence, males are more active than females, and European Americans are

Contract grant sponsor: National Institute of Nursing Research (Institutional and Individual Postdoctoral National Research Service Awards to LBR); Contract grant numbers: 5 T32 NR07073-08, 1 F32 NR07509-01A1.

Contract grant sponsor: University of Michigan School of Nursing Award for New Investigators (to LBR).

*Assistant Research Scientist.

†Professor Emerita.

$\ddagger$ Director, Statistical Consulting Team, and Associate Research Scientist.

${ }^{\S}$ Research Associate II.

"Doctoral Candidate.

Published online in Wiley InterScience (www.interscience.wiley.com)

DOI: 10.1002/nur.20042 
more active than other racial groups (GordonLarsen, McMurray, \& Popkin, 1999). However, there is a critical gap in knowledge concerning developmental, gender, and racial differences in perceptions relative to PA that may influence activity patterns among adolescents (Pender, Murdaugh, \& Parsons, 2002). Because perceived exertion (Huddleston) and self-efficacy have been linked to PA participation (McAuley, 1992; Sallis \& Owen, 1999), the purpose of this study was to examine the association between these perceptions as related to an actual episode of PA among African American and European American boys and girls in different age groups.

Lack of PA is identified as one of the primary causes of childhood and adolescent obesity (BarOr et al., 1998). Currently, almost $30 \%$ of youth are classified as being overweight (Troiano \& Flegal, 1998). This pediatric obesity epidemic is a concern because being overweight is reported to track into adulthood and is associated with higher risks of morbidity and mortality (Troiano, Flegal, Kuczmarski, Campbell, \& Johnson, 1995; Malina, 1996). Wang and Dietz (2002) suggested interventions to increase PA as a promising strategy for dealing with the escalating problem of pediatric obesity, associated morbidity and mortality, as well as related health care costs.

The public health goals for PA for youth for the next decade, as outlined in Healthy People 2010 (USDHHS, 2000), are to increase to $85 \%$ the proportion of adolescents who engage in vigorous PA 3 or more days a week for 20 minutes or more per occasion, and to $30 \%$ the proportion of adolescents who participate in moderate PA at least 5 days per week for 30 minutes or more. Before effective interventions to increase PA in youth can be implemented as a means of preventing and/or treating obesity in that population, an in-depth understanding of factors associated with youth PA is crucial.

In social cognitive theory (SCT) self-efficacy is a central influence on exercise behavior (Bandura, 1986). This proposition is supported by the results of a number of studies of adults in which efficacybased programs significantly influenced exercise adherence (McAuley \& Blissmer, 2000). Bandura (1997) defined self-efficacy as the confidence individuals have in their ability to execute specific behaviors. High self-efficacy motivates behavior. In turn, successful enactment or performance of a behavior resulting in pleasurable sensations further enhances self-efficacy in a particular domain.

Researchers have found that interventions that build perceptions of self-efficacy in youth can result in increased PA participation (Sallis \& Owen, 1999; Sallis, Prochaska, \& Taylor, 2000). In one study involving 5th grade students living in a rural, predominately African American community, those categorized as low active had significantly less self-efficacy for seeking social support from significant others for PA than their active counterparts (Pate et al., 1997). In a crosssectional study of junior and senior high school students (grades 9 and 11) representing lower socioeconomic status, working class minorities (Latino 60.2\%, Anglo 21.4\%, Asian $12.0 \%$, and African American 3.7\%), self-efficacy for PA emerged as the variable most highly correlated with vigorous PA among both boys and girls (Zakarian, Hovell, Hofstetter, Sallis, \& Keating, 1994). The findings also indicated that social factors, such as family or friend support for PA, might be instrumental for sustaining vigorous PA. Due to the cross-sectional design of the study, a causal relationship between these variables and PA could not be inferred.

Results from a prospective study of selected social-cognitive determinants of PA, which was conducted in a rural area with a sample consisting of primarily African American children, indicated that PA self-efficacy assessed in the 5th grade predicted vigorous PA 1 year later in the 6th grade for both boys and girls (Trost et al., 1997). Although PA self-efficacy was predictive of moderate plus vigorous PA for the girls, a similar relationship did not emerge for the boys. Given the gender differences with regard to moderate plus vigorous PA identified in the study and the homogeneity of the group studied in terms of race and age, further research is needed in a more diverse sample of youth to determine the dynamics of selfefficacy in relation to gender, race, and developmental stage. In other investigations, self-efficacy regarding the ability to exercise regularly despite obstacles was positively and significantly correlated with PA participation for adolescent boys and girls (Allison, Dwyer, \& Makin, 1999; Reynolds et al., 1990) and also predicted girls' PA 16 months later (Reynolds et al.).

In SCT, Bandura (1986) proposed that cognitions such as self-efficacy predict subjective interpretations of physiological sensations during a behavior as well as the frequency of the behavior. Behavioral enactment or frequent repetition of a behavior, in turn, is identified as a source for increasing self-efficacy. Consistent with this theory, both frequent and pleasurable experiences with PA are critical to increase PA self-efficacy.

Perceptions of effort during exercise are linked reciprocally with self-efficacy, as well as other 
subjective interpretations of the exercise experience. In an investigation involving undergraduate male kinesiology college students, Rudolph and McAuley (1996) reported that higher pre-exercise self-efficacy was significantly related to lower perceived effort during exercise. Lower perceptions of effort were predictive of higher post-exercise self-efficacy scores. McAuley and Courneya (1992) replicated these results among sedentary middle-aged adults. In another investigation, higher perception of effort during exercise was moderately correlated with more negative feeling states. The relationship became significant when the workload was increased to $90 \%$ of maximum capacity (Hardy \& Rajeski, 1989). These findings imply that perception of exertion may need to be considered during the design of interventions for enhancing self-efficacy and promoting positive feelings regarding the exercise experience.

Pender, Bar-Or, Wilk, and Mitchell (2002) focused on the effect of pre-activity self-efficacy among 103 adolescent girls on responses to a standardized episode $\left(60 \% \mathrm{VO}_{2}\right.$ peak) of exercise. The sample was 89\% European American and $11 \%$ other racial origins. Similar to the findings of Rudolph and McAuley (1996) with young men, girls with high self-efficacy scores had lower perceived exertion during activity than those with low self-efficacy scores. Lower perceptions of exertion, in turn, predicted higher post-exercise efficacy. These findings further support the importance of attending to efficacy beliefs and perceptions of exertion in the context of actual PA participation. Because the sample in Pender et al.'s study was not diverse, questions of gender, racial, and developmental differences in exertional and self-efficacy responses to exercise could not be addressed. This limitation was addressed in the current investigation by recruiting a racially and developmentally diverse group of boys and girls as study participants.

Sallis and Owen (1999) recommend that the influence of various determinants of PA, such as PA self-efficacy, be studied systematically in different population subgroups and at different developmental stages. Three stages of development have been used in research to categorize adolescents into varying stages of maturity: early or pre-puberty, middle puberty, and late puberty (Falk, Bar-Or, \& MacDougall, 1992; Pender et al., 2002). Although SCT does not specifically propose developmental differences in efficacy expectations (Feltz \& Chase, 1998), researchers have found that as children mature, their perceptions of their physical ability change and these perceptions may have dramatic effects on PA performance and related physiological sensations such as perceived exertion (Armstrong \& Welsman, 1997; Brodkin \& Weiss, 1990; Chase, 2001). In a comparative study of 10-year-old and 13-year-old boys and girls, older children rated perceived exertion significantly higher than younger children despite a standardized exercise workload (Marinov, Kostianev, \& Turnovska, 2000). Knowledge of the developmental differences in PA self-efficacy and relationships between PA self-efficacy and perceived exertion during activity among various subgroups is important for increasing PA and thereby lowering the risk of obesity throughout childhood and adolescence.

The specific aims of this study, which focused on African American and European American boys and girls in three developmental stages (early, middle, and late), were to: (a) determine if pre-activity self-efficacy is related to perceived exertion during a standardized episode of PA; (b) determine if perceived exertion is related to post-activity self-efficacy; (c) compare perceived exertion of adolescents of different ages, races, and developmental stages during a standardized episode of PA; and (d) determine if self-efficacy for PA is enhanced by successfully completing a standardized episode of PA. Gender, racial, and developmental stage differences, as well as patterns of change across the standardized episode of PA, were determined for each aim. Other variables, including anthropometric measures (height and weight) and fitness level (peak $\mathrm{VO}_{2}$ ), also were measured so that they could be controlled because they might exert independent effects on the outcome variables (Pender et al., 2002). Weight in pounds was converted to kilograms and height in inches was converted to meters for the purpose of determining body mass index (BMI; $\mathrm{kg} / \mathrm{m}^{2}$ ), an indicator of weight status (McArdle, Katch, \& Katch, 1996). In Pender, Bar-Or et al., percent body fat was positively correlated with perceived exertion.

\section{METHOD}

\section{Design}

For this study, a 3 (developmental stage) $\times 2$ (gender) $\times 2$ (race) descriptive design was employed. Repeated measures of perceived exertion were taken and self-efficacy was assessed both preactivity and post-activity. 


\section{Sample}

The sample for the proposed investigation was recruited through cooperation with school administrators and directors of youth programs (e.g., girl/boy scouts), voluntary agencies, religious education classes/youth groups, and pediatricians' offices/well-child clinics in two cities located in one midwestern state. Advertisements for participants through community organizations where children take lessons or gather for recreational purposes also were used. Girls and boys were informed that they must meet the following criteria for participation: (a) healthy with no acute or chronic illnesses or exercise-induced asthma reported by the child or parent, (b) Englishspeaking, (c) not involved in competitive athletics, and (d) inactive during most days of the week. Recruitment continued until complete data were obtained from at least 12 participants in each of the 12 cells associated with the $3 \times 2 \times 2$ design.

Adolescents interested in making an appointment to participate were instructed to contact the researcher by phone. During the phone interaction, the researcher assessed PA participation. Only adolescents reporting irregular PA below levels recommended in the Healthy People 2010 objectives (USDHHS, 2000), which include vigorous PA 3 or more days per week for at least 20 minutes or moderate PA 5 or more days per week for 30 minutes, were scheduled to participate in two separate 1-hour testing sessions. More active adolescents were encouraged to continue with their PA but were informed that they were ineligible to participate in the study. Of 189 recruited, a total of 168 (89\%) African American and European American boys and girls from 9 to 17 years of age provided complete data for analysis.

To determine sample size, estimates of the standard deviation of one of the key variables (PA self-efficacy) and pre-test-post-test correlations of that variable were taken from a preliminary study (Pender, Bar-Or et al., 2002). The standard deviation of this variable in the prior work was 17.25. The pre-post correlation was just slightly over .50. Based upon this information, a minimum of 144 subjects, 12 per group, defined by the 12 combinations of gender, race, and developmental stage, were required to provide at least $80 \%$ power to detect a 10 -point difference (on the 100-point self-efficacy scale) between groups (gender, developmental stage, race) or between pre-activity and post-activity time points. Sufficient power also was provided for testing simple and multiple correlations in regression analysis with as many as ten predictor variables (Cohen,
1988; Hintze, 1996). Because this study included 168 participants, more than ample power was achieved.

Tables 1 and 2 include means and standard deviations for participant characteristics. As can be noted in these tables, fitness level as indicated by peak $\mathrm{VO}_{2}$ was much lower for African American boys in early puberty than for European American boys in the same developmental stage, $t(31)=-2.99, p<.01$. For the African American girls in early puberty, peak $\mathrm{VO}_{2}$ was much lower than that of European American girls in the same developmental stage, $t(22)=-1.63, p=.12$, with the differences again becoming significant in late puberty, $t(28)=-2.70, p<.05$. These findings were taken into consideration in the statistical analysis.

\section{Measures}

The investigation included age-appropriate measures that have been successfully used in previous studies with children or adolescents.

Anthropometric measurements. Height without shoes was measured in inches to the nearest .25 and weight with clothes (T-shirt and shorts) was assessed in pounds to the nearest .10 with a Health-O-Meter (Continental Scale Corporation, Bridgeview, IL) balance scale with height rod. Values for height and weight were the average of three readings obtained during Session 1.

Developmental stage. The Pubertal Development Scale (Peterson, Crockett, Richards, \& Boxer, 1988) was used to determine stage of development. In studies conducted by Peterson and colleagues, alpha coefficients on this scale ranged from .68 to .83 with a median of .77 . Alpha coefficients calculated for this study were .86 for the boys and .87 for the girls. Using the scale in a private setting, boys and girls were asked to rate themselves on growth spurt, body hair growth (underarm), skin changes, and overall development as compared to other boys/girls of a similar age. Response choices included: (1) no; (2) yes, barely; (3) yes, definitely; or (4) development complete. In addition, boys rated themselves on facial hair growth and voice changes and girls responded to questions concerning breast growth and menstruation.

For girls, scores for body hair, breast growth, and menarche $(1=$ no menstruation yet; $2=y e s$, menstruation started) were combined to determine developmental stage (early, middle, or late puberty). A similar approach was used for boys with scores for facial hair, body hair, and deep- 
Table 1. Means and Standard Deviations of Study Variables for Boys Based upon Race and Developmental Stage $(n=85)$

\begin{tabular}{|c|c|c|c|c|}
\hline Developmental Stage & $M$ & $S D$ & $M$ & $S D$ \\
\hline Early & \multicolumn{2}{|c|}{ African American $(n=14)$} & \multicolumn{2}{|c|}{ European American $(n=19)$} \\
\hline Age & 11.2 & 1.2 & 10.8 & .9 \\
\hline Height (in.) & 58.6 & 3.8 & 57.7 & 3.0 \\
\hline Weight (Ibs) & 112.0 & 30.4 & 90.5 & 23.3 \\
\hline $\mathrm{BMI}$ & 22.6 & 4.2 & 19.0 & 3.7 \\
\hline Peak $\mathrm{VO}_{2}$ & 41.5 & 10.6 & 51.4 & 8.4 \\
\hline Pre-activity self-efficacy & 48.3 & 22.4 & 45.3 & 25.4 \\
\hline Post-activity self-efficacy & 48.9 & 25.6 & 55.9 & 19.3 \\
\hline Rating perceived exertion & 12.3 & 2.6 & 13.7 & 2.6 \\
\hline Middle & \multicolumn{2}{|c|}{ African American $(n=13)$} & \multicolumn{2}{|c|}{ European American $(n=13)$} \\
\hline Age & 13.6 & 1.4 & 12.9 & 1.4 \\
\hline Height (in.) & 65.7 & 2.6 & 64.3 & 4.5 \\
\hline Weight (Ibs) & 130.0 & 37.5 & 131.7 & 32.7 \\
\hline $\mathrm{BMI}$ & 21.1 & 5.4 & 22.1 & 3.8 \\
\hline Peak $\mathrm{VO}_{2}$ & 51.3 & 9.6 & 52.0 & 6.4 \\
\hline Pre-activity self-efficacy & 60.9 & 21.4 & 58.1 & 31.3 \\
\hline Post-activity self-efficacy & 70.1 & 17.6 & 67.5 & 33.3 \\
\hline Rating perceived exertion & 11.0 & 2.1 & 11.9 & 2.8 \\
\hline Late & \multicolumn{2}{|c|}{ African American $(n=14)$} & \multicolumn{2}{|c|}{ European American $(n=12)$} \\
\hline Age & 16.0 & .6 & 15.6 & 1.6 \\
\hline Height (in.) & 69.3 & 2.6 & 67.4 & 2.1 \\
\hline Weight (Ibs) & 156.6 & 20.1 & 137.4 & 18.9 \\
\hline $\mathrm{BMI}$ & 23.0 & 2.1 & 21.3 & 3.3 \\
\hline Peak $\mathrm{VO}_{2}$ & 52.0 & 4.0 & 55.8 & 5.3 \\
\hline Pre-activity self-efficacy & 53.3 & 22.7 & 52.4 & 18.4 \\
\hline Post-activity self-efficacy & 67.9 & 24.8 & 76.9 & 17.5 \\
\hline Rating perceived exertion & 11.3 & 2.9 & 10.9 & 1.8 \\
\hline
\end{tabular}

ening of voice combined. When observational and self-reported scores were compared in earlier studies, correlation coefficients as high as .79 were noted (Peterson et al., 1988).

During the exercise session in this study, the researcher and clinician observed the developmental characteristics of each participant. Similar to results reported by Pender, Bar-Or et al. (2002), agreement greater than $90 \%$ was achieved between participant self-report and researcher observation.

Physical activity self-efficacy. Walking Efficacy Scale items (McAuley \& Mihalko, 1998) were used to measure pre-activity self-efficacy at the beginning of Session 1 and post-activity self-efficacy at the end of Session 2. Immediately after experiencing and reporting comfort with a moderately fast walking pace (3.5 miles per hour) on the treadmill during Session 1, participants were asked to complete the Walking Efficacy Scale. The 12-item scale was used to determine degree of confidence in walking at a moderately fast pace without stopping for increasingly longer time periods that progressed by 5 -minutes increments from a 5 -minutes walk to a 60 -minute walk. Participants rated from 0 (not at all confident) to
100 (completely confident) in increments of 10 their level of confidence in completing the walking tasks. In order to determine efficacy strength, confidence ratings were summed and the result was divided by the total number of scale items (McAuley \& Mihalko, 1998). The scale was readministered following standardized treadmill activity in Session 2. In an investigation involving adolescent girls between the ages of 8 and 17, test-retest reliability for the scale was reported to be 99 . Significant positive correlations between PA self-efficacy scores and those of other variables theoretically proposed to be associated with PA self-efficacy, such as PA participation, competence, and enjoyment, provided support for the validity of the scale (Pender, Bar-Or et al., 2002). Alpha levels in this study were .98 for Session 1 and .97 for Session 2.

Fitness level (peak $\mathrm{VO}_{2}$ ). Peak $\mathrm{VO}_{2}$ is the highest oxygen uptake value achieved during a progressive continuous physical fitness test (McArdle et al., 1996). At the end of Session 1, each subject's peak $\mathrm{VO}_{2}$ or maximum aerobic capacity was determined directly by open circuit spirometry using the SensorMedics 2900 Energy Expenditure Unit, a SensorMedics 2000 Tread- 
Table 2. Means and Standard Deviations of Study Variables for Girls Based upon Race and Developmental Stage $(n=83)$

\begin{tabular}{|c|c|c|c|c|}
\hline Developmental Stage & $M$ & $S D$ & $M$ & $S D$ \\
\hline Early & \multicolumn{2}{|c|}{ African American $(n=12)$} & \multicolumn{2}{|c|}{ European American $(n=12)$} \\
\hline Age & 10.1 & .3 & 10.7 & .5 \\
\hline Height (in.) & 57.7 & 2.9 & 57.4 & 2.9 \\
\hline Weight (Ibs) & 98.6 & 22.9 & 89.3 & 21.1 \\
\hline $\mathrm{BMI}$ & 20.7 & 3.7 & 19.1 & 4.1 \\
\hline Peak $\mathrm{VO}_{2}$ & 40.0 & 9.1 & 46.0 & 8.9 \\
\hline Pre-activity self-efficacy & 27.7 & 13.6 & 38.1 & 27.8 \\
\hline Post-activity self-efficacy & 50.6 & 25.1 & 59.0 & 20.4 \\
\hline Rating perceived exertion & 13.5 & 2.7 & 14.0 & 2.1 \\
\hline Middle & \multicolumn{2}{|c|}{ African American $(n=14)$} & \multicolumn{2}{|c|}{ European American $(n=15)$} \\
\hline Age & 11.3 & 1.1 & 11.1 & 1.1 \\
\hline Height (in.) & 60.5 & 2.9 & 60.3 & 2.9 \\
\hline Weight (Ibs) & 111.8 & 29.8 & 113.2 & 28.1 \\
\hline $\mathrm{BMI}$ & 21.3 & 4.8 & 21.7 & 3.8 \\
\hline Peak $\mathrm{VO}_{2}$ & 41.6 & 8.7 & 42.4 & 8.0 \\
\hline Pre-activity self-efficacy & 34.2 & 26.6 & 44.6 & 22.2 \\
\hline Post-activity self-efficacy & 50.5 & 23.0 & 62.2 & 18.1 \\
\hline Rating perceived exertion & 11.9 & 2.7 & 13.3 & 3.1 \\
\hline Late & \multicolumn{2}{|c|}{ African American $(n=18)$} & \multicolumn{2}{|c|}{ European American $(n=12)$} \\
\hline Age & 13.2 & 2.0 & 15.1 & 1.9 \\
\hline Height (in.) & 63.6 & 2.2 & 65.9 & 2.9 \\
\hline Weight (Ibs) & 150.2 & 45.9 & 147.6 & 24.0 \\
\hline $\mathrm{BMI}$ & 25.9 & 7.0 & 23.9 & 3.2 \\
\hline Peak $\mathrm{VO}_{2}$ & 35.7 & 7.0 & 42.3 & 5.7 \\
\hline Pre-activity self-efficacy & 39.9 & 20.3 & 62.5 & 24.4 \\
\hline Post-activity self-efficacy & 50.7 & 22.6 & 79.6 & 15.9 \\
\hline Rating perceived exertion & 13.4 & 3.2 & 12.2 & 2.2 \\
\hline
\end{tabular}

mill, and a MAX-1 SensorMedics in a thermoneutral environment $\left(70-72^{\circ} \mathrm{F}\right)$. A progressivecontinuous treadmill protocol was followed. After having several minutes to become familiar with wearing an expired air collection apparatus (headpiece, mouthpiece, and nose clips) and walking on the treadmill, each subject was provided with a 1minute, $2.5 \mathrm{mph}$ warm-up period at a grade of $0 \%$ on the treadmill. Subsequently, the grade was elevated to $7.5 \%$ and the treadmill speed was increased every 2 minutes until the subject could no longer continue to walk or run despite encouragement to do so (Skinner et al., 1971). Peak $\mathrm{VO}_{2}$ is reported to be reliable in youth when a jogging or running protocol is used (Armstrong \& Welsman, 1997).

Termination of progressive aerobic exercise tests with young individuals is often solely dictated by the point of exhaustion (participant unable to continue despite strong verbal persuasion; Armstrong \& Welsman, 1994, 1997). However, heart rate and respiratory exchange ratio (RER) can serve as a valuable confirmatory marker of having attained peak $\mathrm{VO}_{2}$ (Armstrong, Kirby, McManus, \& Welsman, 1995; Armstrong \& Welsman, 1997). In this study, whether or not participants reached an acceptable peak oxygen uptake value was determined by their meeting at least two of the following three criteria: (1) heart rate greater than 185 beats per minute, (2) RER greater than or equal to .99 , and (3) appearance of signs of fatigue or self-reported exhaustion. These criteria have been identified as appropriate for prepubertal children and adolescents (Armstrong \& Welsman; Rowland, 1993). Heart rate was monitored continuously throughout peak $\mathrm{VO}_{2}$ testing with a Polar Pacer System (Polar Electro, Woodbury, NY), which transmits cardiac electrical impulses from a lightweight chest transmitter directly to a digital wrist receiver. Of the 189 participants, 21 (11\%) did not reach peak $\mathrm{VO}_{2}$ according to the selected criteria and were not included in the data analysis.

For athletes, experts recommend performing exercise testing with activities as closely aligned to the sports activity as possible (Knechtle \& Kopfli, 2001). Thus, walking/running on a treadmill was selected for exercise testing among adolescents as it simulates the PA that they engage in most frequently, can be assessed in a controlled environment, and does not require a high level of physical skill. 
Perceived exertion. During 20 minutes of standardized treadmill activity in Session 2, participants were asked to respond every 4 minutes to Borg (1985) Rating of Perceived Exertion (RPE) Scale, which measures the magnitude of the stress and strain that individuals sense as a result of PA. In order to determine overall perceived exertion, ratings across time were averaged. Scores for this well-established psychophysical scale range from 6 to 20, with a score of 7 representing very, very light exertion and a score of 19 indicating very, very hard exertion. The literature suggests that children 10 years of age or older can reliably rate their perceived exercise intensity, as determined by the heart rate and RPE relationship (Bar-Or, 1977). Significant correlations of .83 and .87 between heart rate and RPE were noted in children 10-17 years of age with and without structural heart defects, respectively (Eakin, Finta, Serwer, \& Beekman, 1992).

Procedure. Procedures for protecting the rights of human subjects were approved by the university Health Sciences Institutional Review Board. Two separate 1-hour testing sessions occurring 6-8 days apart were conducted in a university laboratory setting and involved questionnaire completion and PA on a treadmill.

At the initial session, the study was explained to the parent(s) and child. Each parent and child was asked to sign an informed consent form and assent form, respectively. Parents remained in a waiting area while their child was in the testing sessions. Demographic data, as well as information pertaining to PA patterns, developmental stage, anthropometric measurements, PA self-efficacy, and peak $\mathrm{VO}_{2}$, were obtained. Boys and girls were taught to respond to the scale measuring perceived exertion to indicate (when asked by the researcher) how hard they felt they were working during peak $\mathrm{VO}_{2}$ testing. The test was terminated when they reported they could no longer continue the activity.

At the second laboratory session, use of the scales was reviewed. To both individually tailor and standardize the PA task, boys and girls walked/ran for 20 minutes on the treadmill at a speed equivalent to $60 \%$ of their peak $\mathrm{VO}_{2}$ as determined in the first testing session. A treadmill was used to operationalize moderately fast walking in a laboratory environment, as this was a PA task that all adolescent participants could perform. A stationary bicycle was not selected, as some adolescents involved in prior pilot work reported that they did not have a bicycle and therefore did not know how to ride one. RPE was obtained at 4-minutes intervals throughout the standardized exercise task to identify changes in psychophysical responses. The time needed to respond to the scale was only 5 seconds and did not interfere with the treadmill PA protocol. A Power Point computer presentation was used to present the RPE scale to the participants at the appropriate time and responses were manually recorded. Heart rate was monitored throughout the entire 20-minute treadmill session. Participants were informed that communication with them would be kept to a minimum so that they could focus on the treadmill activity. No encouragement or positive feedback related to performance was provided. Immediately following the standardized treadmill activity, participants completed the PA self-efficacy measure.

\section{Data Analysis}

All participants achieving peak $\mathrm{VO}_{2}(n=168$ or $89 \%$ ) in the first session returned for the second session and provided complete data for analysis. Pearson bivariate correlational analyses were conducted for the total group, as well as separately for the boys and the girls, to identify relationships among PA self-efficacy in Sessions 1 and 2, peak $\mathrm{VO}_{2}$, and RPE. Factorial ANOVA, factorial ANCOVA, linear regression, and hierarchical regression were used to determine if pre-activity self-efficacy predicted perceived exertion, if perceived exertion predicted post-activity selfefficacy, and if any effects differed by gender, race, or developmental stage. Repeated measures ANOVA was employed to compare RPE among subgroups during the standardized episode of PA, to determine if changes occurred in efficacy from before to after the activity episode, and to identify whether patterns of change differed by gender, race, and developmental stage. One-way ANOVA with Scheffe post-hoc analysis and independent $t$-tests were used to determine specific developmental stage and gender differences, respectively. A .05 probability level was required for significance.

\section{RESULTS}

\section{Relationships among Study Variables}

For the total group, pre-activity self-efficacy in Session 1 was positively correlated with post-activity self-efficacy in Session $2(r=.64$, $p<.001)$, as well as peak $\mathrm{VO}_{2}(r=.29, p<.001)$, and negatively related to $\operatorname{RPE}(r=-.21, p<.01)$. Post-activity self-efficacy was positively correlated with peak $\mathrm{VO}_{2}(r=.32, p<.001)$ and nega- 
tively correlated with RPE $(r=-.38, p<.001)$. Peak $\mathrm{VO}_{2}$ was not related to exertion. BMI was not correlated with either self-efficacy or exertion but was correlated negatively with peak $\mathrm{VO}_{2}$ $(r=-.58, p<.001)$ consistent with the findings of Marinov, Kostianev, and Turnovska (2002).

When data were analyzed separately for boys and girls (see Table 3), post-activity self-efficacy was positively correlated with pre-activity selfefficacy and negatively correlated with RPE for both genders. For boys, but not girls, pre-activity self-efficacy was negatively correlated with RPE.

\section{Pre-Activity Self-Efficacy, and Perceived Exertion During Activity}

For the total group of adolescents, regression analysis showed that greater pre-activity selfefficacy predicted lower perceived exertion, $F$ $(1,166)=7.68, p<.01$, and explained a significant but small amount of the variance (4\%; see Table 4). Because of a significant gender by preactivity self-efficacy interaction, $F(1,148)=4.45$, $p<.05$, linear regression analysis was conducted separately for the boys and girls to determine how much of the variance in RPE was explained by mean pre-activity self-efficacy. For the boys, preactivity self-efficacy emerged as a significant predictor of RPE and explained $14.6 \%$ of the variance, $F(1,83)=14.24, p<.001$. This relationship indicated that boys with high pre-activity self-efficacy (Session 1) reported lower exertion while performing the standardized treadmill activity (Session 2). In contrast, for the girls, preactivity self-efficacy failed to predict perceived exertion (RPE) during the treadmill activity. The effect of efficacy on RPE did not differ by race or developmental stage for either boys or girls. However, a significant main effect of developmental stage on RPE emerged for the total group of adolescents, $F(2,148)=4.01, p<.05$. Adolescents in early puberty $(M=13.36, S D=2.53)$ had significantly greater RPE than those in either middle $(M=12.07, S D=2.79, p<.05)$ or late $(M=12.09, S D=2.80, p<.05)$ puberty, $F(2,165)=4.22, p<.05$.

\section{Perceived Exertion and Post-Activity Self-Efficacy}

Hierarchical regression analysis was used to determine if RPE predicted post-activity selfefficacy (see Table 4). Peak $\mathrm{VO}_{2}$ and pre-activity self-efficacy were controlled because these two variables were significantly correlated with postactivity self-efficacy. Results showed that the variance in post-activity self-efficacy was significantly accounted for by RPE after the researchers controlled for peak $\mathrm{VO}_{2}$ and pre-activity selfefficacy, $F(3,164)=50.83, p<.001$. Lower RPE predicted greater post-activity self-efficacy. The effect of RPE on post-activity self-efficacy did not differ by gender, race, developmental stage, or by combinations of these variables.

\section{Differences among Groups in Perceived Exertion}

Repeated measures ANOVA was conducted using time of measurement, every 4 minutes, as a withinsubjects factor, and gender, developmental stage, and race as between-subjects factors. A significant main effect of time on RPE indicated that RPE increased as the session progressed, $F=$

Table 3. Pearson Correlation Matrix of Study Variables by Gender

\begin{tabular}{|c|c|c|c|c|c|}
\hline & 1 & 2 & 3 & 4 & 5 \\
\hline \multicolumn{6}{|l|}{ Boys $(n=85)$} \\
\hline 1. Efficacy: Session 1 & 1.00 & & & & \\
\hline 2. Efficacy: Session 2 & $.67 * * *$ & 1.00 & & & \\
\hline 3. Peak $\mathrm{VO}_{2}$ & .21 & $.48 * * *$ & 1.00 & & \\
\hline 4. Rating perceived exertion & $-.38 * * *$ & $-.45^{* * *}$ & -.20 & 1.00 & \\
\hline 5. BMI & -.16 & -.20 & $-.58 * * *$ & -.01 & 1.00 \\
\hline \multicolumn{6}{|l|}{ Girls $(n=83)$} \\
\hline 1. Efficacy: Session 1 & 1.00 & & & & \\
\hline 2. Efficacy: Session 2 & $.59 * * *$ & 1.00 & & & \\
\hline 3. Peak $\mathrm{VO}_{2}$ & .20 & .11 & 1.00 & & \\
\hline 4. Rating perceived exertion & .03 & $-.27^{*}$ & .10 & 1.00 & \\
\hline 5. BMI & -.02 & -.00 & $-.64^{* * *}$ & -.09 & 1.00 \\
\hline
\end{tabular}


Table 4. Pre-Activity Self-Efficacy, Perceived Exertion, and Post-Activity Self-Efficacy ANOVA Tables

\begin{tabular}{|c|c|c|c|}
\hline Variable & $B$ & $S E$ of $B$ & Beta \\
\hline Pre-activity self-efficacy & -.02 & .01 & $-.21 * *$ \\
\hline \multicolumn{4}{|c|}{$\begin{array}{l}\text { Note: } R^{2}=.04 \\
* p<.05 \\
* * p<.01 \\
* * * p<.001 \\
\text { Dependent variable: rating of perceived exertion. }\end{array}$} \\
\hline Variable & $B$ & $S E$ of $B$ & Beta \\
\hline \multicolumn{4}{|l|}{ Step 1} \\
\hline $\begin{array}{l}\text { Peak VO} \\
\text { Step } 2\end{array}$ & .79 & .18 & $.32 * * *$ \\
\hline $\begin{array}{l}\text { Peak } \mathrm{VO}_{2} \\
\text { Pre-activity self-efficacy }\end{array}$ & $\begin{array}{l}.38 \\
.57\end{array}$ & $\begin{array}{l}.15 \\
.06\end{array}$ & $\begin{array}{l}.16^{*} \\
.59^{* * *}\end{array}$ \\
\hline \multicolumn{4}{|l|}{ Step 3} \\
\hline $\begin{array}{l}\text { Peak } \mathrm{VO}_{2} \\
\text { Pre-activity self-efficacy } \\
\text { Perceived exertion }\end{array}$ & $\begin{array}{r}.33 \\
.53 \\
-2.11\end{array}$ & $\begin{array}{l}.14 \\
.06 \\
.50\end{array}$ & $\begin{array}{r}.13^{*} \\
.55^{* * *} \\
-.24^{* * *}\end{array}$ \\
\hline
\end{tabular}

Note: $R^{2}=.11 ;$ Step $1 ; R^{2}$ change $=.32$ for Step 2 and .06 for Step 3.

${ }^{*} p<.05$

$* * p<.01$

$* * * p<.001$

Dependent variable: post-activity self-efficacy.

$(4,153)=131.24, p<.001$. The interaction of time with developmental stage was significant, $F(8,308)=2.52, p=.01$. Scheffé post-hoc analysis with repeated measures showed a trend for adolescents in early puberty to report greater exertion than those in both middle and late puberty. This trend was stronger during the latter part of the standardized treadmill activity and proved to be significant at 16 minutes, $F(2,165)=5.70$, $p<.01$, (early vs. middle, $p<.05$; early vs. late, $p<.01)$ and 20 minutes, $F(2,165)=6.18, p<$ .01 (early vs. middle, $\mathrm{p}<.05$; early vs. late, $p<.01)$. Interactions of time with gender were significant, $F(4,153)=2.38, p=.05$. Girls tended to report greater exertion than boys during each of the time periods, with increasing levels of significance as time progressed, 8 minutes, $t$ $(166)=-1.92, p=.06 ; 12$ minutes, $t(166)=$ $-2.55, p<.05 ; 16$ minutes, $t(166)=-2.93$, $p<.01$; and 20 minutes, $t \quad(166)=-2.95$, $p<.01$. Neither the time-by-race interaction nor the three-way interactions proved significant.

\section{Pre- and Post-Activity Self-Efficacy Differences among Groups}

When repeated measures ANOVA was used to determine if changes occurred in self-efficacy for PA from before to after the episode of activity, the conservative Greenhouse-Geisser procedure was used to adjust for violation of the sphericity assumption (SPSS, 1999). Results showed a significant main effect of time indicating an increase in self-efficacy from Session 1 to Session 2, $F(1,158)=84.31, p<.001$.

The race-by-gender interaction was the only significant two-way interaction, $F(1,158)=4.96$, $p<.05$. Averaged across time (pre-activity vs. post-activity) and developmental stages, selfefficacy was significantly lower for African American girls than for the other three racegender groups, $F(3,164)=5.55, p<.01$. The time-by-gender interaction approached significance, $F(1,158)=3.63, p=.06$. Independent t-tests indicated significantly, $t(166)=3.07$, $p<.01$, higher pre-activity self-efficacy for boys $(M=52.46, S D=23.99)$ than girls $(M=41.02$, $S D=24.37)$, but no significant differences between boys $(M=63.65, S D=24.62)$ and girls $(M=58.12, S D=22.82)$ regarding post-activity self-efficacy.

Of the three-way interactions, significant findings occurred only for the time-by-gender-bydevelopmental stage interaction, $F(2,158)=3.98$, $p<.05$. Because of the significance of the interaction, data from the boys and girls were examined separately. A significant time by developmental stage interaction emerged for the 


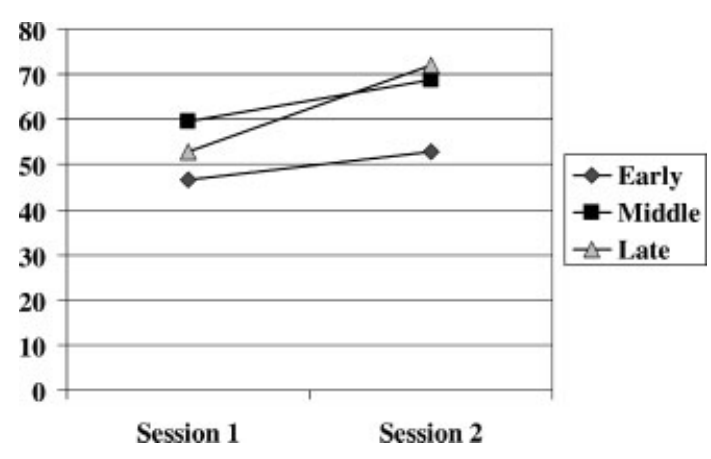

FIGURE 1. Mean efficacy for boys by pubertal group.

boys, $F(2,82)=3.38, p<.05$. Figure 1 shows a significant increase in efficacy from Session 1 to 2 for boys in middle, $t(25)=-2.94, p<.01$, and late, $t(25)=-5.21, p<.001$, puberty, but not for those in early puberty. Although no developmental stage differences in pre-activity self-efficacy emerged for the boys, boys in early puberty had significantly lower post-activity self-efficacy than middle, $F(2,82)=5.83, p<.05$, and late, $F(2,82)=5.83, p<.05$, pubertal boys. Girls in early, $t(23)=-5.84, p<.001$, middle, $t(28)=$ $-3.91, p=.001$, and late, $t(29)=-3.41, p<.01$, puberty had a significant increase in efficacy from Session 1 to 2 . No developmental stage differences in either pre- or post-activity self-efficacy were noted for the girls (see Fig. 2).

\section{DISCUSSION}

In SCT, self-efficacy is proposed as a powerful determinant of frequency of behavior and interpretations of physiological sensations during behavior. Behavioral experiences, in turn, influence self-efficacy (Bandura, 1986; 1997). Results of this study partially support these assertions. Among boys, higher perceived self-efficacy was asso-

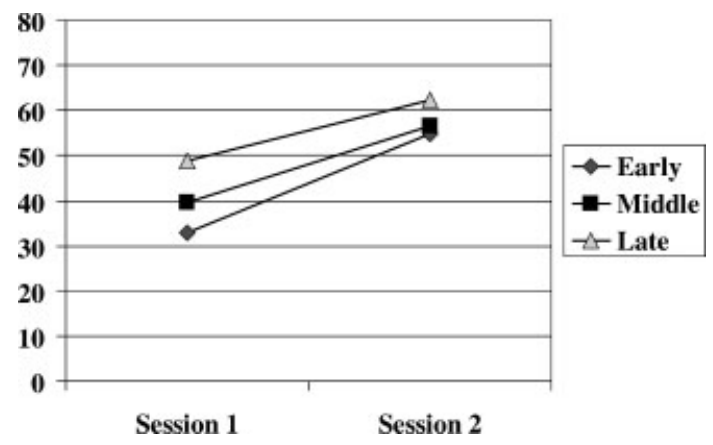

FIGURE 2. Mean efficacy for girls by pubertal group. ciated with lower perceived exertion during exercise and lower perceived exertion was associated with higher self-efficacy after exercise. These findings are consistent with earlier studies of male kinesiology students (Rudolph \& McAuley, 1996) and suggest that future interventions to increase PA among boys need to include a component to enhance PA self-efficacy. For the girls in this investigation, pre-activity self-efficacy was not related to perceived exertion, but lower perceived exertion was associated with higher self-efficacy after exercise. The lack of relationship between pre-exercise self-efficacy and perceived exertion is not in agreement with earlier studies of predominantly European American adolescent girls (Pender, Bar-Or et al., 2002). Because the variance in perceived exertion was similar for boys and girls, this gender difference in the relationship between pre-activity self-efficacy and perceived exertion could not be explained by clustering of scores at the higher end of the exertion scale for girls, which would have limited the amount of variance that could be explained. Future research is needed with larger racially and ethnically diverse groups of girls to further explore the effects of self-efficacy on exertional responses to PA in order to inform counseling interventions intended to increase PA self-efficacy.

In this study, the significant increase for both boys and girls in self-efficacy after completing the exercise task supports the importance of successful performance for enhancing self-efficacy or confidence in a particular behavioral domain. Findings of this study suggest that individually tailored mastery experiences compatible with the fitness level of the child should be incorporated into PA interventions to encourage regular PA. For girls, decreasing uncomfortable perceptions of exertion during exercise by encouraging enjoyable activities at appropriate levels of effort appears essential to successfully promoting regular activity. This strategy may be particularly important for African American girls who reported the lowest level of PA self-efficacy of all groups. Interventions to increase PA self-efficacy should focus on: (a) providing positive PA experiences that minimize perceptions of discomfort, (b) mobilizing social sources of efficacy enhancement, such as modeling of PA by significant others (Bandura, 1986; e.g., peers, family members, educators, and health professionals), and (c) persuading children and adolescents that regular PA is an important and enjoyable part of everyday life. Research findings of a positive correlation between support for PA from parents and siblings and youth PA involvement (Aarnio, Winter, 
Kujala, \& Kaprio, 1997; Zakarian et al., 1994) suggest that combining social support, selfefficacy, and positive experiential components in interventions to increase PA may be promising.

In terms of the developmental dynamics explored in this study, younger children reported higher perceived exertion than older children. This finding does not agree with that of Marinov et al. (2000) who found that older children rated perceived exertion higher than younger children. Higher perceived exertion among boys in early puberty in the current study may have resulted in the lack of increase in self-efficacy following exercise observed in that group. Research that explores the effects of developmental changes on the experience of exercise would provide valuable information for tailoring PA counseling interventions to children at various levels of maturation.

Several limitations of the present study should be noted: (a) the sample bias, as the study may have attracted volunteers who were favorably predisposed to PA, and (b) the social desirability bias, as data collection was conducted in a university laboratory setting and biased responses may have occurred even though participants were informed that each question should be answered as honestly as possible. A larger study with a control group is recommended to provide additional evidence that the exercise tasks alone and not other factors, such as increasing comfort with the laboratory environment over time, were responsible for the significantly higher post-activity self-efficacy scores.

In summary, the findings of this study have important implications for health professionals who provide services to children and adolescents. PA counseling interventions should encourage adolescents to engage in activities with appropriate exertional characteristics suited to their level of physical fitness and individual preferences. High exertion activities threaten PA selfefficacy and jeopardize motivation for regular PA participation, particularly among sedentary adolescents (McAuley \& Blissmer, 2000). Developing multifaceted interventions incorporating behavioral approaches (Grey et al., 2004) that enhance self-efficacy for PA and enjoyment of PA represents one promising approach for clinicians to increase PA among adolescents of all ages and decrease the escalating epidemic of obesity.

\section{REFERENCES}

Aarnio, M., Winter, T., Kujala, U.M., \& Kaprio, J. (1997). Familial aggregation of leisure-time physical activity - a three generation study. International Journal of Sports Medicine, 18, 549-556.
Allison, K.R., Dwyer, J.J.M., \& Makin, S. (1999). Selfefficacy and participation in vigorous physical activity by high school students. Health Education and Behavior, 26, 12-24.

Armstrong, N., Kirby, B.J., McManus, A.M., \& Welsman, J.R. (1995). Aerobic fitness of pre-pubescent children. Annals of Human Biology, 22, 427-441.

Armstrong, N., \& Welsman, J. (1997). Young people and physical activity. New York: Oxford University Press.

Bandura, A. (1986). Social foundations of thought and action: A social cognitive theory. Englewood Cliffs, NJ: Prentice-Hall.

Bandura, A. (1997). Self-efficacy: The exercise of control. New York: W. H. Freeman.

Bar-Or, O. (1977). Age-related changes in exercise perception. In G. Borg (Ed.), Physical work and effort (pp. 255-266). New York: Pergamon.

Bar-Or, O., Foreyt, J., Bouchard, C., Brownell, K.D., Dietz, W.H., Ravussin, E., et al. (1998). Physical activity, genetic, and nutritional considerations in childhood weight management. Medicine and Science in Sports and Exercise, 30, 2-10.

Borg, G. (1985). An introduction to Borg's RPE Scale. Ithaca, NY: Movement Publications.

Brodkin, P., \& Weiss, M.R. (1990). Developmental differences in motivation for participating in competitive swimming. Journal of Sport and Exercise Psychology, 12, 248-263.

Chase, M.A. (2001). Children's self-efficacy, motivational intentions, and attributions in physical education and sport. Research Quarterly for Exercise and Sport, 72, 47-54.

Cohen, J. (1988). Statistical power analysis for the behavioral sciences (2nd ed). Hillsdale, NJ: Lawrence Erlbaum.

Eakin, B.L., Finta, K.M., Serwer, G.A., \& Beekman, R.H. (1992). Perceived exertion and exercise intensity in children with or without structural heart defects. The Journal of Pediatrics, 120, 90-93.

Falk, B., Bar-Or, O., \& MacDougall, J.D. (1992). Thermoregulatory responses of pre-, mid-, and latepubertal boys to exercise in dry heat. Medicine and Science in Sports and Exercise, 24, 688-694.

Feltz, D.L., \& Chase, M.A. (1998). The measurement of self-efficacy and confidence in sport. In J.L. Duda (Ed.), Advances in sport and exercise psychology measurement (pp. 65-80). Morgantown, WV: Fitness Information Technology.

Gordon-Larsen, P., McMurray, R.G., \& Popkin, B.M. (1999). Adolescent physical activity and inactivity vary by ethnicity: The National Longitudinal Study of Adolescent Health. Journal of Pediatrics, 135, 301306.

Grey, M., Berry, D., Davidson, M., Galasso, P., Gustafson, E., \& Melkus, G. (2004). Preliminary testing of a program to prevent type 2 diabetes among high-risk youth. Journal of School Health, 74, 10-15.

Hardy, C.J., \& Rajeski, W.J. (1989). Not what, but how one feels: The measurement of affect during exercise. Journal of Sport and Exercise Psychology 11, 304317. 
Hintze, J.L. (1996). PASS (power analysis and sample size for windows) 6.0 user's guide. Kaysville, UT: Number Cruncher Statistical Systems.

Huddleston, J.S. (2002). Exercise. In C.L. Edelman \& C.L. Mandle (Eds.), Health promotion throughout the lifespan (pp. 319-351). St. Louis, MO: Mosby.

Knechtle, B., \& Kopfli, W. (2001). Treadmill exercise testing with increasing inclination as exercise protocol for wheelchair athletes. Spinal Cord, 39, 633-636.

Malina, R. (1996). Tracking of physical activity and physical fitness across the lifespan. Research Quarterly for Exercise and Sport, 67(Suppl), S48.

Marinov, B., Kostianev, S., \& Turnovska, T. (2000). Ventilatory response to exercise and rating of perceived exertion in two pediatric age groups. Acta Physiological Pharmacology Bulgaria, 25, 93-98.

Marinov, B., Kostianev, S., \& Turnovska, T. (2002). Ventilatory efficiency and rate of perceived exertion in obese and non-obese children performing standardized exercise. Clinical Physiological Function Imaging, 22, 254-260.

McArdle, W.D., Katch, F.I., \& Katch, V.L. (1996). Exercise physiology: Energy, nutrition, and human performance (4th ed). Baltimore: Williams \& Wilkins.

McAuley, E. (1992). The role of efficacy cognitions in the prediction of exercise behavior in middleaged adults. Journal of Behavioral Medicine, 15, 65-88.

McAuley, E., \& Blissmer, B. (2000). Self-efficacy determinants and consequences of physical activity. Exercise and Sport Sciences Reviews, 28, 85-88.

McAuley, E., \& Courneya, K.S. (1992). Self-efficacy relationships with affective and exertion responses to exercise. Journal of Applied Social Psychology, 22, 312-326.

McAuley, E., \& Mihalko, S.L. (1998). Measuring exercise-related self-efficacy. In J.L. Duda (Ed.), Advances in sport and exercise psychology measurement (pp. 371-390). Morgantown, WV: Fitness Information Technology.

McGinnis, J.M. (1992). The public health burden of a sedentary lifestyle. Medicine and Science in Sports and Exercise, 24(6 Suppl), S196-S200.

Pate, R.R., Trost, S.G., Felton, G.M., Ward, D.S., Dowda, M., \& Saunders, R. (1997). Correlates of physical activity behavior in rural youth. Research Quarterly for Exercise and Sport, 68, 241-248.

Pender, N.J., Bar-Or, O., Wilk, B., \& Mitchell, S. (2002). Self-efficacy and perceived exertion of girls during exercise. Nursing Research, 51, 86-91.

Pender, N.J., Murdaugh, C.L., \& Parsons, M.A. (2002). Health promotion in nursing practice (4th ed). Upper Saddle River, NJ: Prentice Hall.

Peterson, A.C., Crockett, L., Richards, M., \& Boxer, A. (1988). A self-report measure of pubertal status: Reliability, validity, and initial norms. Journal of Youth and Adolescence, 17, 117-133.
Reynolds, K.D., Killen, J.D., Bryson, S.W., Maron, D.J., Taylor, C.B., Maccoby, N., et al. (1990). Psychosocial predictors of physical activity in adolescence. Preventive Medicine, 19, 541-551.

Rowland, T.W. (1993). Aerobic exercise testing protocols. In T.W. Rowland (Ed.), Pediatric laboratory exercise testing (pp. 19-41). Champaign, IL: Human Kinetics.

Rudolph, D.L., \& McAuley, E. (1996). Self-efficacy and perceptions of effort. Journal of Sport and Exercise Psychology, 18, 216-223.

Sallis, J.F., \& Owen, N. (1999). Physical activity and behavioral medicine. Thousand Oaks, CA: Sage.

Sallis, J.F, Prochaska, J.J., \& Taylor, W.C. (2000). A review of correlates of physical activity of children and adolescents. Medicine and Science in Sports and Exercise, 32, 963-975.

Skinner, J.S., Bar-Or, O., Bergsteinova, V., Bell, C.W., Royer, D., \& Buskirk, E.R. (1971). Comparison of continuous and intermittent tests for determining maximal oxygen intake in children. Acta Paediatrica Scandinavica Supplement, 217, 24-28.

SPSS. (1999). SPSS advanced models 9.0. Chicago, IL: Author.

Stone, E.J., McKenzie, T.L., Welk, G.J., \& Booth, M.L. (1998). Effects of physical activity interventions in youth: Review and synthesis. American Journal of Preventive Medicine, 15, 298-315.

Troiano, R.P., \& Flegal, K.M. (1998). Overweight children and adolescents: Description, epidemiology, and demographics. Pediatrics, 101, 497-504.

Troiano, R.P., Flegal, K.M., Kuczmarski, R.J., Campbell, S.M., \& Johnson, C.L. (1995). Overweight prevalence and trends for children and adolescents. Archives of Pediatrics and Adolescent Medicine, 149, 1085-1091.

Trost, S.G., Pate, R.R., Saunders, R., Ward, D.S., Dowda, M., \& Felton, G. (1997). A prospective study of the determinants of physical activity in rural fifthgrade children. Preventive Medicine, 26, 257-263.

United States Department of Health and Human Services [USDHHS]. (1996). Physical activity and health: A report of the Surgeon General. Atlanta, GA: U.S. Department of Health and Human Services, Centers for Disease Control and Prevention, National Center for Chronic Disease Prevention and Health Promotion.

United States Department of Health and Human Services [USDHHS]. (2000). Healthy people 2010: conference edition in two volumes. Washington, DC: Author.

Wang, G., \& Dietz, W.H. (2002). Economic burden of obesity in youths aged 6 to 17 years: 1979-1999. Pediatrics, 109, e81.

Zakarian, J.M., Hovell, M.F., Hofstetter, C.R., Sallis, J.F., \& Keating, K.J. (1994). Correlates of vigorous exercise in a predominantly low SES and minority high school population. Preventive Medicine, 23, 314-321. 